\title{
Numerical Approach for the Implementation of the Interaction of Pyrolysis Gases and Combustion Products in an Aluminium- Melting Furnace
}

\author{
Gültekin, R. ${ }^{a *}$; Rückert, $\mathrm{A}^{\mathrm{a}}$; Pfeifer, $\mathrm{H}^{\mathrm{a}}{ }^{\mathrm{a}}$ \\ a) \\ Department for Industrial Furnaces and Heat Engineering, RWTH Aachen University; Kopernikusstraße 10, 52074 Aachen, Germany
}

\begin{abstract}
Aluminium is a key material in modern society and serves the needs because of the unique properties of the metal and its alloys. Scientific evidence and rational economic theories have repeatedly demonstrated that recycling is the most critical and efficient pathway to sustainable human development. Aluminium products like Used Beverage Cans or Containers (UBCs) has been alloyed with other elements to fulfil consumer requirements and contain organic material due to paint and lacquer coatings on the body. The melting and pre-treatment of scrap has an emphasized role in the recycling chain of contaminated aluminium products. The relationship between the amount of contamination, pre-treatment and melting procedure and dross formation attains crucial attention in order to enhance the energy efficiency in existing furnaces. Therefore, understanding the melting and pre-treatment processes includes statistical surveys and systemic modelling. In the present work, numerical simulations were carried out using the commercial software FLUENT for generating a helpful tool in evaluating operational conditions. The main perspective is to analyze the relevant operational conditions inside an aluminium-melting furnace employing oxygen-fuel burner, which is capable to run in the flameless combustion mode. To cope with the challenge of simulating flameless combustion (highly diluted chemical conversion) proved detailed chemistry mechanisms are involved. Further crucial aspect is to evaluate additional in house written codes for the evaporation and gas release due to contaminated input material. Within the scope of the project P5 of the AMAP (Advanced Metals And Processes) research cluster in Aachen a virtual remelting furnace is set up as a CFD (Computational Fluid Dynamics) simulation for evaluating the terms of combustion, pyrolysis/ thermolysis, interaction of combustion products and pyrolysis gases and other crucial phenomena.
\end{abstract}

(C) 2017 The Authors. Published by Elsevier Ltd.

Peer-review under responsibility of the organizing committee of INFUB-11

Keywords: Combustion, Flameless combustion, CFD simulation, Chemical schemes, Industrial furnaces, Aluminium recycling

* Corresponding author. Tel.: +49 (0) 241-80 29541

E-mail address: gueltekin@iob.rwth-aachen.de 


\section{Introduction}

The global demand for aluminium is increasing year by year $(+7.8 \%$ or 1.8 Mio tonnes in 2010 compared with the previous year [1]). The production of aluminium is linked to excessive use of valuable energy; especially the production of primary aluminium is energy-intensive. Only $5 \%$ of the energy to produce primary aluminium (14.239 $\mathrm{kWh} / \mathrm{t}[2])$ is required for remelting and refining of aluminium scrap [1]. Political and economic orientation to the recycling economy requires the advancement of the remelting process, since more and more contaminated scraps arrive in this cycle. The majority of secondary aluminium is used in automotive sector, followed by machine construction, buildings and packaging industry [1]. Aluminium scrap like baled UBCs contain in general substantial amount of paint, plastic and liquids like water. Increased level of organic content reduces metal recovery and therefore the metal yield. With the view to ensuring efficiency and the conservation of resources, promoting the use of these organic contaminations as valuable energy source is desirable. While some furnaces address this potential (twin chamber furnaces), the status quo is still the reverberatory one chamber furnace equipped with gas burners. The latest generation of burners is designed to reduce exhaust gas emissions. Low NOx emission burners, like FLOX burners, reflect the stage of the art of aluminium melting. The crucial difference of the flameless combustion principle is the mixing of air and fuel firstly with reaction products via a strong recirculation, resulting in a nonluminous "flame". The absence of temperature peaks (spatial and temporal) is the major benefit of this type of combustion, which leads to a nearly uniform combustion throughout the entire furnace gas volume [3]. The reactive flow has a major impact on the heat transfer to the load. Thereby it is mostly dominated by gas combustion due to the heating burners in the furnace and pyrolysis/ thermolysis reaction caused by organic contamination of the charge. Numerical modelling has become an essential tool in industrial processes for evaluating and optimization of industrial processes. The prediction of the emissions pollutants, temperature and velocity pattern support the understanding of the combustion and melting process. Even in cases of more complex procedure like FLOX (Flameless Combustion) numerical calculations supply reliable values. The attempt to develop a CFD model for achieving higher metal recovery and less environmental impact postulates capturing the whole complexity. Chemical reaction mechanisms, high temperature effects, burnedoff reactions and the shifting scrap properties like the contamination are some of the parts of this complex system. As mentioned, the characteristics of the flameless combustion differ strongly from the conventional methods of burning. Numerical predictions that have proven in standard furnaces are not working well in predicting flameless conditions. Developing models, which can deal with the flameless specifics, are imperative, due to the potential for more widespread implementation of these efficiency-increasing techniques.

Several experiments within scope of AMAP were carried out in order to gain property data of input material, as well as exhaust gas composition and output material in dependency of boundary conditions, pre-treatment and combustion modes. Fluent database of materials extended with the obtained data and numerical model is validated by the measurement results.

\section{Investigated Furnace and Burner}

The laboratory scale reverberatory furnace (figure 1) with total capacity of $120 \mathrm{~kg}$ load of aluminium and is not intended to be a scale model of an industrial furnace, rather it is a testing model to evaluate i. A. the interaction between combustion atmosphere and the charge material and the dross produced during melting of certain scrap. It is equipped with one oxygen-gas burner, shown in figure 2. In case of fuel/air combustion, a tube-in-tube arrangement is available. Natural gas is injected in the inner and air in the outer tube. Permitting fuel/oxygen combustion the outer tubes on the both side of the tube-in-tube configuration are used to inject pure oxygen. While the Oxy-gas burner is of interest the following description, consider only this burner. It has three different combustion modes: standard mode, semi-flameless mode and flameless mode. The firing rate of the burner is $40 \mathrm{~kW}$. 


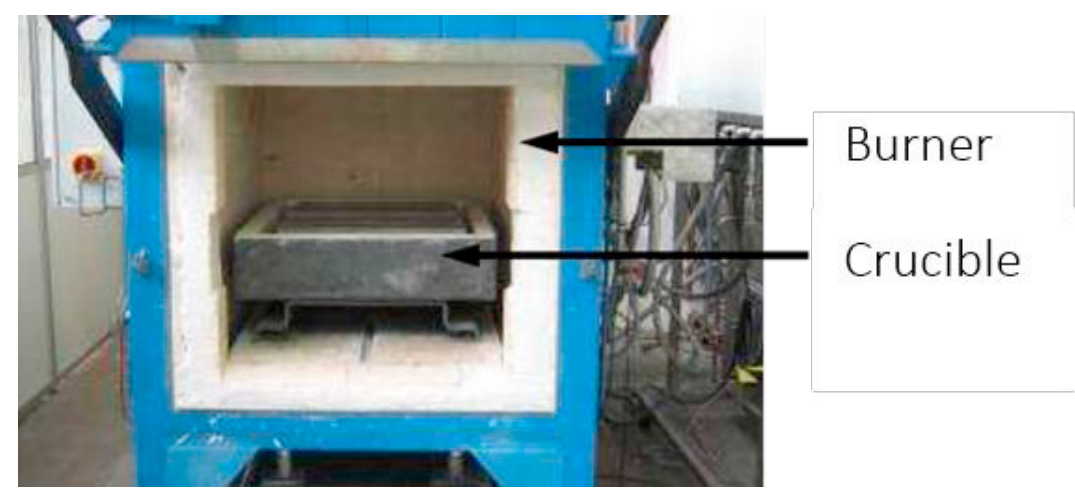

Fig. 1. Laboratory scale reverberatory furnace

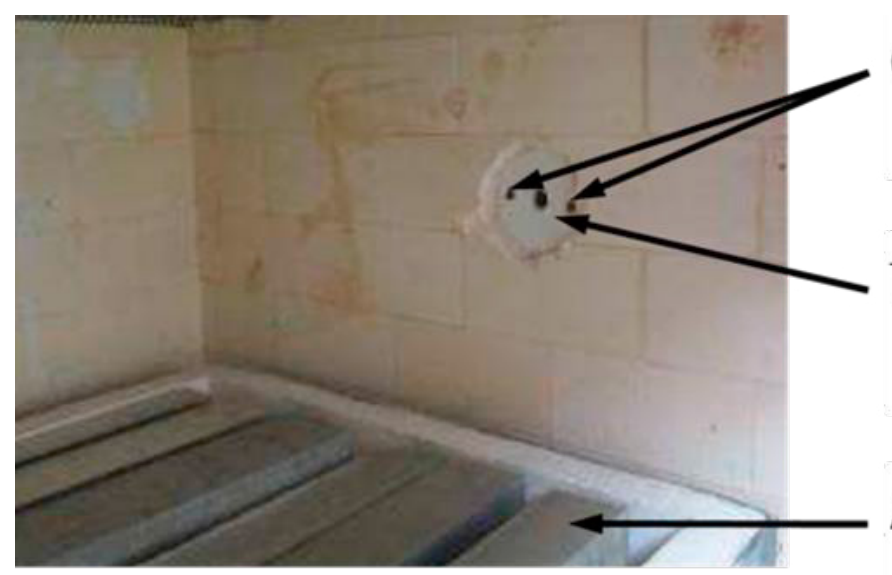

Oxygen lances

Tube-in-tube configuration

Fig. 2. Investigated oxygen-fuel burner

The real melting process corresponds to a transient procedure with several stages like loading solid charge into the furnace, heating up to the melting temperature, melting it completely, and subsequently holding the liquid load warm for a given time sequence. Simulating a dynamic three-phase aluminium melting process is impossible to achieve for several reasons. This complexity can be overcome by subdividing the simulation into stages. Each stage is a simpler snapshot than the overall complex system.

\section{$\underline{\text { Sequence 1: Heating Process }}$}

The charge (UBC bale) is inserted into the furnace and is directly exposed to the open flame, while the burner runs in the flameless mode. Radiation from the walls of the furnace and the combustion reaction dries the load followed by gasification, pyrolysis and combustion of the bounded combustible elements takes place. Due to this process, species like vaporized water, carbon dioxide, carbon monoxide and some hydrocarbons are generated.

\section{Sequence 2: Melting Process}

The second stage involves phase change from solid to liquid aluminium.

\section{Sequence 3: Holding Process}

The holding sequence of liquid charge is the last time sequence. During this period, the middle lance is used to inject oxygen into the furnace and a conventional flame is evident. Liquid Aluminium built a dross layer, which serves 
as isolation.

\section{Model Set-up}

The CFD model is generated by SolidWorks with slight simplifications, and the commercial software ICEM is utilized to set up the matching mesh of three million hexahedra cells, given in Figure 3. The internal reference geometry dimensions are $1138 \mathrm{~mm}$ x $1355 \mathrm{~mm}$ x $963 \mathrm{~mm}$. The load and slag is involved by separating the gas volume in the crucible several times to maintain flexibility in defining the width of both depending specific cases. The commercial CFD ANSYS Fluent 16.5 is utilized to simulate the fluid behaviour.

a)

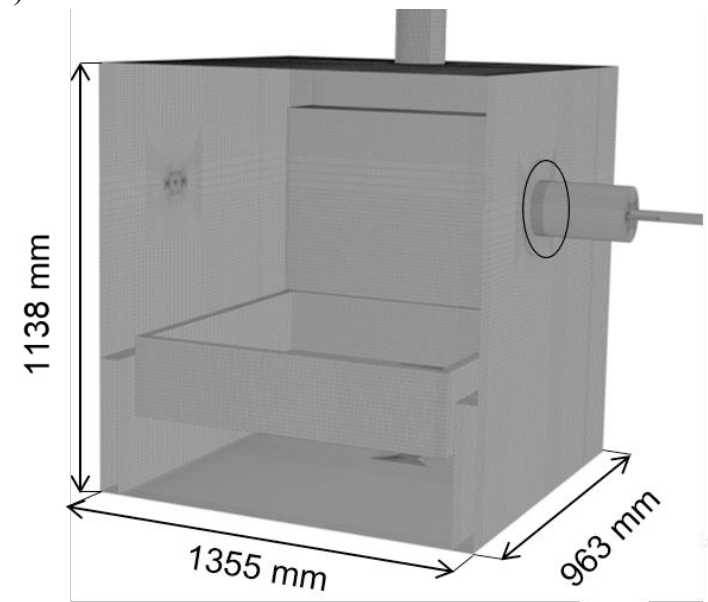

b)

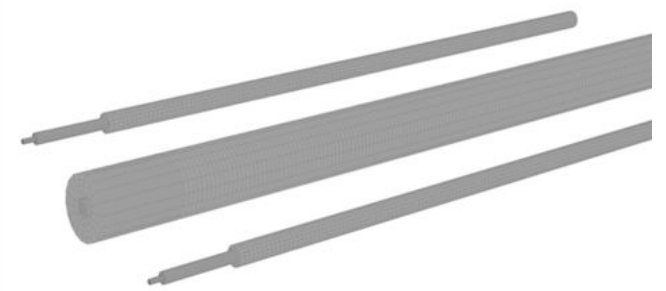

Fig. 3. CFD geometry and grid of the (a) furnace and (b) burner

The interaction of combustion and turbulence is modelled with EDC using the 2-step mechanisms or the GRI-Mech 3.0 gas phase mechanisms code [4], depending on the relevant sequence. Chemical combustion models exist in variation with different complexity and accuracy. Some models manage to cope with all steps and species while others reduce these to a simplified mechanism with limited number of reactions and less species. "While this simplified chemistry includes adequate information to predict flow patterns and local heat transfer, these models lack sufficient information to accurately predict NOx and CO production"[3]. The GRI-MECH 3.0 gas phase mechanisms code is widely accepted and used in the research field as well as in the industry [4]. Accounting every species would require large amount of computer resources and computational time. The decision has been made to account the most important reactions while keeping the number of species as small as possible with the aim to predict the ignition and extension phenomena reliable. Depending on the type of combustion, various relevant parameters to describe the properties of significant material or boundary conditions have to be chosen. Radiation is involved in the form of the DO (Discrete Ordinates) model, which is implemented for grey gas radiation. The cell based WSGGM (Weighted Sum of Grey Gas Model) model is used to approach the gas absorption coefficient. The fluid behaviour is simulated by using the k- $\omega$-SST model. Gas properties like heat capacity and the dynamic viscosity, which vary in a combustion regime over a wide range, are calculated by piecewise polynomial curve fitting in two temperature ranges. The individual species mass fraction is used as a weight function to calculate the properties for the mixture. Properties of solid bale and dross like dimensions, density, porosity, contamination and humidity content, heat transfer coefficient $\lambda$ are obtained by the work of AMAP team members. Literature values and internal database of industry partners is used to tap characteristics of different liquid aluminium alloys. 


\subsection{Model of Sequence 1: Heating Process}

The heating period started with charging the baled UBC scrap directly into the crucible. The oxygen lances are active and increased velocities at the inlets caused a sufficient recirculation. Achieving $373 \mathrm{~K}$ leads to the evaporation of the liquid content in the bale. In a temperature range between $573 \mathrm{~K}$ and $700 \mathrm{~K}$ pyrolysis gases are released into the gas volume.

Combustion and heat transfer

Due to the prevailing conditions the flameless mode is given, therefore detailed chemical mechanisms are involved, while every combustion approach relying on simplifications of fast chemistry are not suitable here [5-11]. The temperature distribution is homogenous without any flame front, whereby the average temperature is around $1373 \mathrm{~K}$. Mainly radiation caused the heating of the charge.

$\underline{\text { Solid load }}$

UBS bale properties differs in a wide range depending on supplier and other factors like storage conditions. Fortunately, being in a consortium environment enable the access to various types of bales leading to a properties database. Figure 4 shows some examples of examined UBC bales cross-sections to emphasize the variation. This database is implemented into the Fluent model and can be chosen depending on the case.

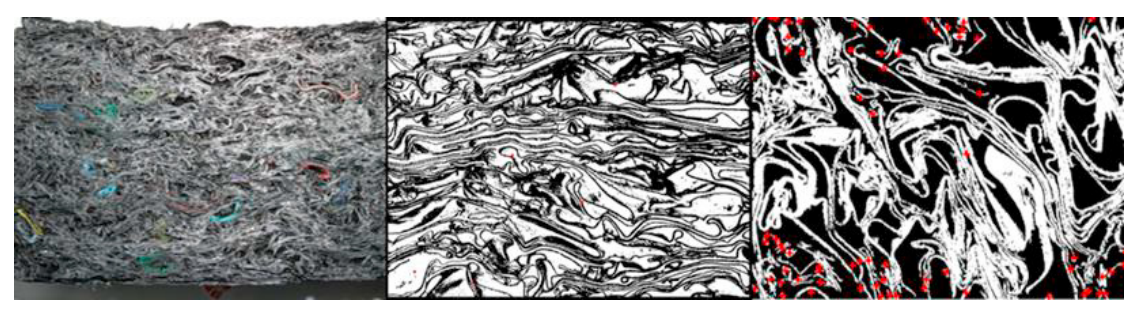

Fig. 4. UBC bale cross section

\section{Evaporation}

Evaporation of water or other liquid content in aluminium scrap bales occurs before the release of gases caused by organic contamination and has an impact of the heating. This occurrence is taken into account by a UDF (User Defined Function). Every numerical cell of the bale is checked if the boiling temperature is achieved. In case of achieved 373 $\mathrm{K}$, the water content in the cell is released as vapour. A memory for every cell guaranteed to release vapour only once during the heating period. Latent heat created by this event is also taken into account. While the UDF is tested in a trial model, it will be addressed in further work for numerical simulation of the whole melting sequence in a transient case.

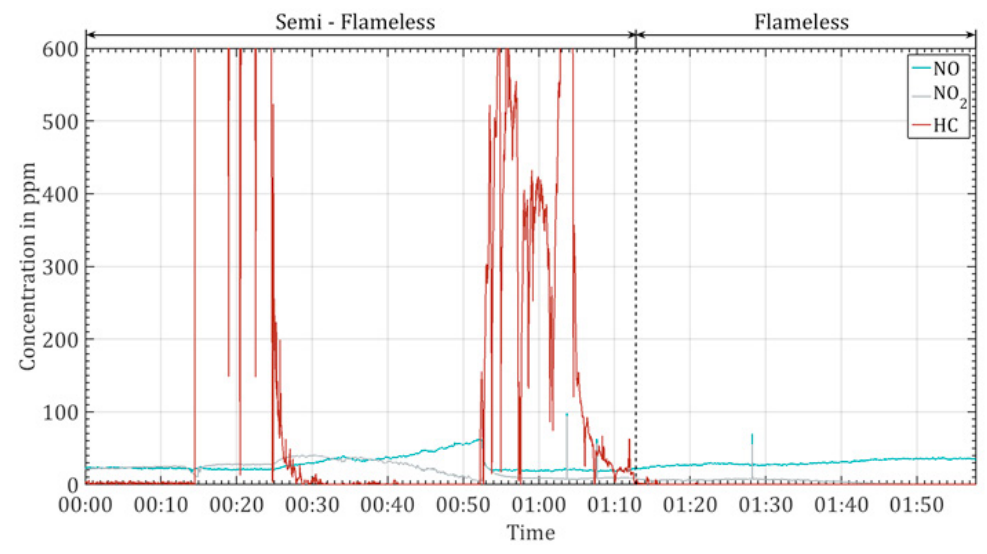

Fig. 5. Diagram of measured released hydrocarbon during the heating sequence 
Gas release due to organic contamination

Short and long chained hydrocarbons released by heated bales in dependency of the boundary conditions, as given in the diagram (Figure 5) obtained during a measurement campaign. Temperature has the main influence on this behaviour. For the model introduced in this paper, methane is declared as the equivalent for released gases. The release occurs abrupt in case of achieving the sufficient temperature (highest peak). Here again the UDF is successfully applied in a transient trial simulation.

\subsection{Model of Sequence 3: Holding Process}

The melting period is followed up by the holding sequence. The crucible contains molten aluminium alloy. On the surface of the liquid bath, a dross layer is existent. Burner performance is decreased and the inner lances supply oxygen.

\section{Combustion and heat transfer}

For the simulation of the conventional combustion during the holding sequence in Fluent embedded two-step methane mechanism is employed, generating a conventional flame with high temperature peaks at the flame front and generally increased average temperature up to $2073 \mathrm{~K}$. Dross layer reduce heat transfer into the bath by radiation and convection. Heat transfer to the liquid aluminium occurs mainly due to conduction.

\section{$\underline{\text { Liquid load }}$}

Aluminium alloy characteristics of grade 3xxx and 5xxx are taken of literature and internal databases of industrial partners and the fluent material database is extended by these materials. For example, properties of liquid aluminium alloys 3104 and 5182 at $973 \mathrm{~K}$ are given in Table 1.

Table 1. Properties of aluminium alloys

\begin{tabular}{llll}
\hline Property & Unit & AA3104 & AA5182 \\
\hline density & $\mathrm{kg} / \mathrm{m}^{3}$ & 2375.2 & 2326.0 \\
specific heat & $\mathrm{J} / \mathrm{kg} \mathrm{K}$ & 1173.3 & 1185.0 \\
latent-heat & $\mathrm{J} / \mathrm{kg}$ & 385847 & 391846 \\
boiling point & $\mathrm{K}$ & 2470 & 2470 \\
thermal conductivity & $\mathrm{W} / \mathrm{m} \mathrm{K}$ & 76.16 & 77.98 \\
viscosity & Pa.s & $1.15 \mathrm{E}-03$ & $1.15 \mathrm{E}-03$ \\
\hline
\end{tabular}

\section{$\underline{\text { Dross }}$}

Physical, chemical and mechanical properties of dross in dependency of input material (charge) are measured within the scope of AMAP and added to the material database, as well. Table 2 gives an overview of mean values of dross gained during melting of UBC bales with coating and high amount of impurities as iron cans, cables, plastic screw caps and plastic.

Table 2. Properties of dross example

\begin{tabular}{lll}
\hline Property & Unit & Value \\
\hline Density: & $\mathrm{g} / \mathrm{cm}^{3}$ & 0.91 \\
Volatile loss (glowing loss at $\left.450^{\circ} \mathrm{C}\right)$ & $\%$ & 8 \\
Moisture content $\left(\operatorname{loss}\right.$ at $\left.105^{\circ} \mathrm{C}\right)$ & $\%$ & $<1.7$ \\
Thermal conductivity & $\mathrm{W} / \mathrm{mK}$ & 4.7
\end{tabular}




\section{Results and Validation}

The examples given in this section emphasize the result of the current model. For validation purpose, several planes and iso-surfaces generated. Temperature and velocity pattern predicted by simulations are validated against measurements done on the real furnace. Temperature distribution at the mid plane given in Figure 6 (a) shows the heating case. Characteristics of the flameless combustion as homogenous temperature distribution and the absence of temperature peaks are predicted by the simulation in a satisfactory manner.

While during the holding sequence, the predicted temperature distribution differs completely from the predicted values during the heating period (Figure 6 (b)). Measurement campaign on the lab scale furnace supplied a database of temperature and gas composition in dependency of burner performance. The measured values are obtained by suction pyrometer during the trials.

a) Heating sequence temperature distribution

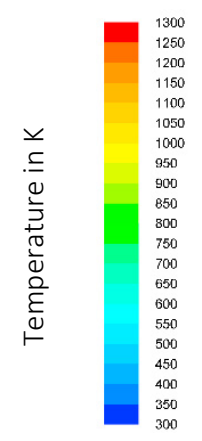

b) Holding sequence temperature distribution

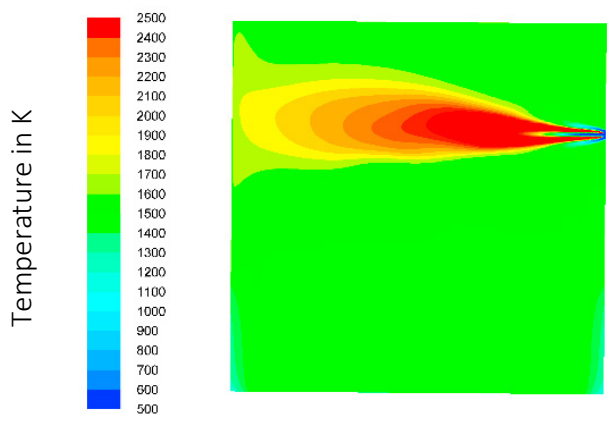

Fig. 6. Temperature distribution in the middle plane at the burner central lances in both sequences

The suction pyrometer offers the practical advantage of measuring only the gas temperature without getting any distortions caused by direct radiation components. During the trials, it was installed from the access through the ceiling and was shifted during the trials along the y-axis.

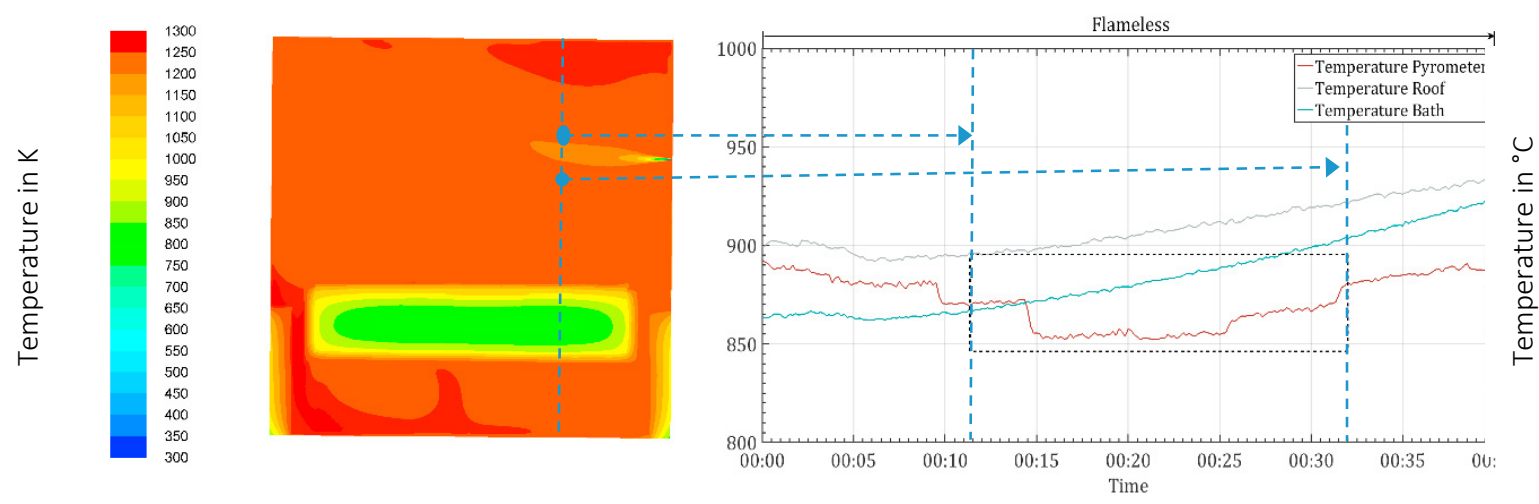

Fig. 7. Correlation between predicted and measured temperature distribution

Start position of the suction pyrometer is $5 \mathrm{~cm}$ below the ceiling. The suction pyrometer was shifted every five minutes about five $\mathrm{cm}$ downwards. At the burner centerline, a temperature trop of approximately 10 to $20 \mathrm{~K}$ is apparent. This phenomenon shows a high coincidence with the predicted temperature distribution by the numerical model given in Figure 6 (a). Measured and predicted temperatures at the ceiling and at the exhaust gas pipe has a mean deviation of 9.3 and $16 \%$, respectively. 


\section{Summary and Outlook}

A numerical set-up for the heating and holding procedure of an aluminium-melting furnace is generated. While the focus was to capture the gas volume reactions including the gas release of hydrocarbons due to organic contamination of the input material. Further effort achieved by generating a properties database for input material and for dross generation to feed into the Fluent database. The numerical simulation of the combustion process inside a furnace was developed on the base of well-validated GRI-MECH chemical data and of the built-in combustion reactions in Fluent. Evaporation and Gas release out of scrap is implemented using UDF with slight differences of the reaction scheme it is able to reflect the main properties of the gas reactions and describe satisfactory good experimental data for temperature distribution in the furnace and the exhaust gas content. The performed simulations of the heating sequence proved to be helpful. Gas release over time in dependency of temperature in a transient heating sequence is the further milestone.

The research leading to these results has been carried out within the framework of the AMAP (Advanced Metals And Processes) research cluster at RWTH Aachen University, Germany consisting of the Aleris Rolled Products Germany GmbH, Constellium, Hydro Aluminium Rolled Products GmbH, Trimet Aluminium SE and the RWTH Aachen institutes IME Process Metallurgy and Metal Recycling as well as IOB Industrial Furnaces and Heat Engineering.

\section{References}

[1] Gesamtverband der Aluminiumindustrie e.V. (GDA), Düsseldorf, Germany

[2] Primary aluminium smelting energy intensity, www.world-aluminium.org

[3] Peters, N. Multi-scale combustion and turbulence, Proc.Combst. Inst. 32 1-25, 2009

[4] Smith G. P.; Golden D. M.; Frenklach, M et al., http://www.me.berkeley.edu/gri_mech

[5] Orsino, S.; Weber R.; and Bollettini, U.: Numerical simulation of combustion of natural gas with high-temperature air Combust. Sci. technol. 170

[6] Mancini M.; Schwöppe, P.; Weber, R.; Orsino, S.: On mathematical modelling of fameless combustion Combust. flame 150

[7] Mancini, R.; Weber, R. and Bollettini, U.: Predicting NOx emissions of a burner operated in flameless oxidation mode Proc. Combust. Inst. 29

[8] Tabacco, D.; Innarella C.; Bruno C.: Theoretical and numerical investigation on flameless combustion Combust sci. tech. 174

[9] Lupant, D.; Pesenti, B.; Evrard, P.; and Lybaert, P.: Numerical and experimental characterization of a self-regenerative fameless oxidation burner operation in a pilot-scale furnace Combust sci. tech. 179

[10] Christo, F. C. and Dally, B. B.: Modeling turbulent reacting jets issuing into a hot and diluted coflow. Combust. flame 142

[11] Galletti, C.; Parente, C. and Tognotti, L.: Numerical and experimental investigation of a mild combustion burner Combust flame 15 